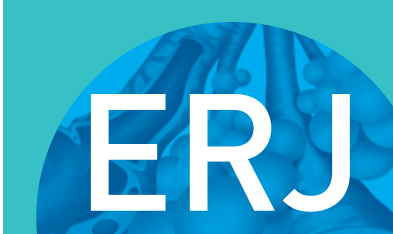

open research
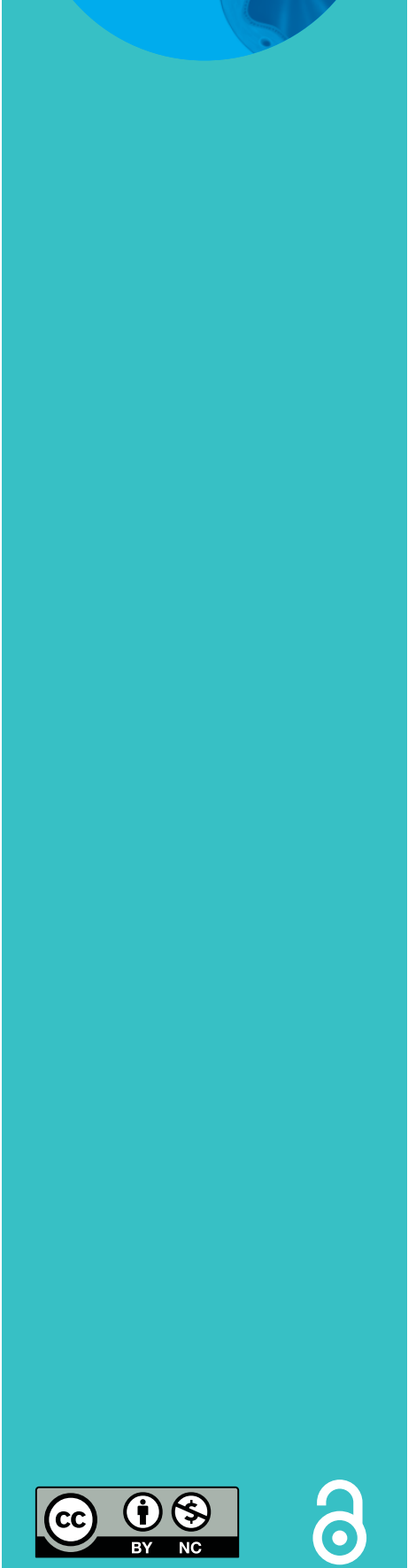

\section{Spacer devices for inhaled therapy: why use them, and how?}

\author{
Walter Vincken ${ }^{1}$, Mark L. Levy ${ }^{2}$, Jane Scullion ${ }^{3}$, Omar S. Usmani ${ }^{4}$, \\ P.N. Richard Dekhuijzen ${ }^{5}$ and Chris J. Corrigan ${ }^{6}$ on behalf of the ADMIT group
}

\author{
Affiliations: \\ ${ }^{1}$ Respiratory Division, University Hospital Brussels (UZ Brussel), Vrije Universiteit Brussel, Brussels, Belgium. \\ ${ }^{2}$ Harrow Primary Care Trust, London, UK. \\ ${ }^{3}$ University Hospitals of Leicester, Leicester, UK. \\ ${ }^{4}$ Imperial College London, London, UK. \\ ${ }^{5}$ Radboud University Medical Centre, Nijmegen, The Netherlands. \\ ${ }^{6}$ Faculty of Life Sciences and Medicine, King's College London/Guy's and St Thomas's NHS Foundation Trust, \\ London, UK.
}

\section{Correspondence:}

Chris J. Corrigan, King's College London Faculty of Life Sciences and Medicine, Dept of Asthma, Allergy and Lung Biology, Fifth Floor, Tower Wing, Guy's Hospital, Great Maze Pond, London SE1 9RT, UK.

E-mail: chris.corriganakcl.ac.uk

ABSTRACT We present an extensive review of the literature to date pertaining to the rationale for using a spacer/valved holding chamber (VHC) to deliver inhaled therapy from a pressurised, metered-dose inhaler, a discussion of how the properties of individual devices may vary according to their physical characteristics and materials of manufacture, the potential risks and benefits of ancillaries such as valves, and the evidence that they contribute tangibly to the delivery of therapy.

We also reiterate practical recommendations for the correct usage and maintenance of spacers/VHCs, which we trust offer practical help and advice to patients and healthcare professionals alike.

@ERSpublications

Every patient treated with a pMDI should own and regularly use a spacer/VHC, and know how to use it properly, both for routine preventer therapy and in an emergency, and how to keep it clean and keep an eye out for faults http://ow.ly/EDs730keDOw

Cite this article as: Vincken W, Levy ML, Scullion J, et al. Spacer devices for inhaled therapy: why use them, and how? ERJ Open Res 2018; 4: 00065-2018 [https://doi.org/10.1183/23120541.000652018].

Copyright $\odot$ ERS 2018. This article is open access and distributed under the terms of the Creative Commons Attribution Non-Commercial Licence 4.0. 


\section{Introduction}

Development of the pressurised metered-dose inhaler (pMDI) in the mid-1950s paved the way for widespread, personalised delivery of topical inhaled therapy for the pharmacological management of obstructive airways diseases (asthma and chronic obstructive pulmonary disease (COPD)), which has since proved its worth in terms of benefit/risk ratio and tolerability. An important weakness of pMDI devices, however, is their propensity to be used suboptimally or incorrectly [1], a problem that has been recognised since their inception and that is unfortunately still prevalent today. Incorrect pMDI usage may have knock-on effects on efficacy, safety and patient compliance.

Maximising airway deposition of a pMDI-delivered drug requires a slow $\left(30 \mathrm{~L} \cdot \mathrm{min}^{-1}\right)$, deep inhalation commencing immediately after pMDI activation followed by a breath-hold pause of $\geqslant 4 \mathrm{~s}$ and optimally up to $10 \mathrm{~s}$ [2]. Even with optimal technique and modern hydrofluoroalkane propellants, however, pMDIs deliver, at best, only $\sim 20 \%$ of the emitted dose to the lower airways, leaving $\sim 80 \%$ in the oropharynx [2]. With suboptimal or incorrect technique, this fraction is further reduced, potentially to zero.

The concept of activating the pMDI into a spacer (an additional reservoir placed between the mouthpiece of the pMDI and the mouth of the patient) or a valved holding chamber (VHC) (a reservoir with a one-way valve permitting airflow into, but not out of, the patient's mouth) prior to inhalation was developed in the 1950s [3,4] to address some, but not all, of the problems and potentially critical errors when using a pMDI. Use of a spacer/VHC slows down the aerosolised particles emitted from the pMDI, which may further increase lung deposition of the respirable fine particles, although the clinical significance of this effect is not well established. It certainly significantly filters out and thereby reduces oropharyngeal deposition of the larger particles emitted from a pMDI, even with "perfect" technique [5].

The correct use of a spacer/VHC negotiates with the common and potentially critical problem of poor coordination of activation of the pMDI with commencement of inhalation [1]. Although some synchrony of activation of the pMDI with inhalation is still desirable when using a spacer/VHC, the patient has a lot more time to accomplish this effectively. Breath-activated pMDIs are also available for the delivery of some inhaled drugs and these may also assist with poor coordination, but do not deliver all of the potential advantages of a spacer/VHC. No inhaler device can fully obviate the propensity for patients to breathe in too quickly (although some more recent devices warn patients of this using a whistle activated above a flow threshold, while another device whistles if used correctly) or to fail to hold their breath following inhalation. In the late 1970s, larger VHCs were developed with the additional intention of creating a reservoir for the aerosolised particles, enabling their administration by tidal breathing [4].

All patients using a pMDI to take inhaled medications should be advised to use a spacer/VHC for both regular and emergency medications, and in particular those patients who are poor at coordinating activation of the pMDI with inhalation. This includes children using a pMDI (using a face mask below the age of 3 years) [6], the elderly and infirm, and those with compromised comprehension or manual dexterity [7]. Such patients can be given their medication by their family members or care givers using the pMDI-spacer/VHC combination.

Extensive studies have shown that in situations where emergency administration of a bronchodilator is indicated for an acute exacerbation of COPD or asthma in both children and adults, the use of a pMDI with a spacer/VHC is at least as effective and safe as nebulised therapy [8-11], and may indeed reduce emergency room waiting times and systemic unwanted effects of bronchodilator therapy. Compared with nebulised therapy, it is also cheaper, more convenient, portable and relatively maintenance free [12].

Despite recommendations in national and international guidelines that pMDIs should be used with a spacer/VHC [13], they appear to be widely underused: previous estimates vary from $10 \%$ in the UK in 1990 to $46 \%$ in Canada in 2008 [14]. In a cross-sectional survey of patients with asthma or COPD presenting to the emergency department in the USA, fewer than half of those using a pMDI owned a spacer/VHC and only half of these had used it on the day of presentation [15]. Having a primary care physician and a history of prior hospitalisation for asthma or COPD were factors independently associated with spacer/VHC ownership. The likelihood of spacer/VHC usage also appears to vary with the type of obstructive lung disease: in a study in New Zealand, 40\% of COPD patients used a spacer/VHC as compared with only $15 \%$ of asthma patients [16].

The aim of this article is to provide, for patients and healthcare professionals, an overview of the advantages and potential disadvantages of spacers/VHCs, describe the situations in which a spacer/VHC is most likely to be useful and indicated, and address practical issues such as correct handling, priming and maintenance. We trust that it may help promoting regular and reliable usage and maintenance of spacers/ VHCs. Based on extensive scrutiny of the published literature and, where evidence is lacking, the consensus amongst the ADMIT members, this paper adds to and complements previous reviews [14, 17-21], 
and in particular the report of the joint Task Force of the European Respiratory Society and the International Society for Aerosols in Medicine [20].

\section{Choosing a spacer}

Not all spacers are equal: performance may vary according to their size/volume, shape, material of manufacture and propensity to become electrostatically charged, their mode of interface with the patient, and the presence or otherwise of valves and feedback devices (table 1).

\section{Size}

Small-volume spacers (up to $100 \mathrm{~mL}$ ) usually are nonvalved, tube-like extensions of the mouthpiece of the pMDI. They are least cumbersome but also least likely to obviate the need for additional coordination between actuation of the pMDI and commencement of inhalation on the part of the patient.

Medium- (100-350 mL) and large-volume $(>700 \mathrm{~mL})$ spacers usually incorporate a unidirectional valve at their mouthpiece end, allowing inhalation from, but not exhalation into, the spacer. These devices are therefore called VHCs and allow more leeway in the time in which the patient has to commence inhalation after activating the pMDI or allowing delivery by tidal breathing. They are more cumbersome and less portable. Theoretical considerations suggest that a spacer/VHC should ideally be $100-700 \mathrm{~mL}$ in volume, and should provide a distance of $\geqslant 10 \mathrm{~cm}$ between the pMDI and the patient's mouth [22].

Why else may volume of the spacer/VHC be important? For one thing, it determines the number of breaths necessary to empty it, which is important in small children (generating tidal breaths of $10 \mathrm{~mL} \cdot \mathrm{kg}^{-1}$ body weight). Spacer/VHC size does not affect fine particle fraction [23] but may influence the aerosol profile and thereby the variability of the particle content of the emitted dosage with time during inhalation $[24,25]$. In a large-volume spacer/VHC, the particle cloud becomes static prior to inhalation, providing evenly distributed delivery of the aerosol throughout the inhalation. In a small-volume spacer, the particle cloud remains turbulent and may deliver an initial "burst" of concentrated aerosol followed by comparatively aerosol-free air. Thus, while the delivery of all of the particles from a single pMDI actuation is more vulnerable to reduction by insubstantial inhalation using a large-volume, as compared with a small-volume, spacer/VHC [26], a large-volume device may target the entire bronchial tree in a more uniform fashion [24].

\section{Valves}

Valveless, open-tube spacers simply distance the pMDI from the patient's oropharynx. VHCs, which contain a low-resistance, one-way valve situated behind the mouthpiece, retain the aerosol within the device until the patient inhales and prevent exhaled breath from re-entering the VHC. This allows the VHC to be used with tidal breathing as well as with a single, deep inspiration. A significant proportion (15 out of 80 in the quoted study) of very young children $(<24$ months of age) is unable to generate sufficient (subatmospheric) inspiratory pressure to open the unidirectional valve of various commercially available VHCs [27]. This ability should be examined before they are prescribed. Valves may become jammed if soiled or damaged, a problem easily detected and possibly solved by cleaning or replacement of the device, provided that the patient is aware.

\section{Material of manufacture}

Plastic/polycarbonate/polymer spacers/VHCs do not conduct electricity and are therefore susceptible to electrostatic charging of their inner surface [18]. Electrostatic charge attracts aerosol particles, which may considerably (by up to 50\%) reduce the aerosol dosage available for inhalation. Although electrostatic charge can be reduced and lung deposition of aerosol correspondingly improved by priming the spacer/VHC

\section{TABLE 1 Spacer/valved holding chamber features or characteristics}

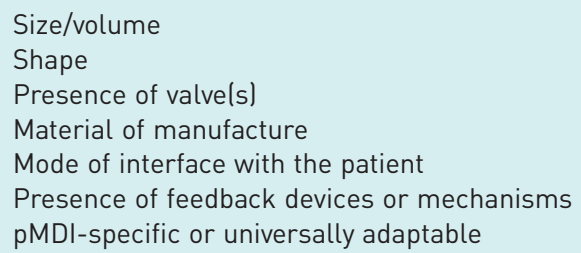

pMDI: pressurised, metered-dose inhaler. 
with multiple dosages from a pMDI, this is wasteful of medication; similar effects accrue, to an extent, with repeated use of the device and by rinsing it in soapy water (see later) [28-30]. In order to minimise re-accumulation of electrostatic charge after cleaning and washing, nonconducting spacers should be drip-dried, avoiding rubbing or wiping of the inner surface.

Metallic (steel or aluminium) spacers/VHCs and some plastic spacers/VHCs with an antistatic inner lining (made of electrostatic charge-dissipative material) do not need priming since they are conducting and do not accumulate electrostatic charge. As a result, fine-particle mass and lung deposition of aerosolised drug is increased [7, 29, 31, 32] and may theoretically enable dosage reduction, but this is not guaranteed [33], while possibly increasing systemic exposure [34].

\section{Interface with the patient}

Spacers/VHCs with a facemask rather than a mouthpiece may be preferable for children $<3$ years of age [35] and for all patients incapable, for any reason, of making a slow, measured inspiratory effort while holding a mouthpiece between the teeth. Children over the age of 3 years often continue to use facemasks and, if so, technique should always be checked as spacers/VHCs with facemasks designed for use with small children may provide a poor seal with the face, resulting in impaired or variable dosage delivery [36]. A tight (but comfortable) mask-to-face seal using sufficient force is important but may be difficult to achieve in young or uncooperative patients [37-39]. When using a facemask, the dead space between the mouth and valve of the spacer/VHC should be minimised. Besides facial seal and dead space, other design considerations for an optimal mask for young children and infants include contour, flexibility, transparency, weight and cost [40].

\section{Feedback devices and mechanisms}

Some spacers are provided with a whistle that sounds if the patient inhales too quickly. It should be made clear to the patient that the whistle is not intended to sound. Conversely, at least one spacer is now available with a facemask designed for young children that whistles when the correct breathing technique has been mastered and the fit is correct, reassuring healthcare providers and parents that medication is being delivered.

\section{pMDI-specific versus universally adaptable spacers/VHCs}

It is important that the pMDI fits tightly into the spacer/VHC. Some spacers/VHCs are provided with a soft rubber inlet that accepts pMDIs of various sizes. When using a non-dedicated pMDI-spacer/VHC combination, it is important to verify that the spray exiting the pMDI remains directed into the centre of the spacer/VHC. Other spacers/VHCs are designed for specific pMDIs and will not accept any others. If the mouthpiece of the pMDI is larger than the inlet on the spacer/VHC, the combination is obviously not suitable. When the mouthpiece is smaller than the inlet, tape is sometimes used to effect a seal but we would suggest that this is inadvisable because such practice does not guarantee that the aerosol plume is directed into the centre of the spacer/VHC.

\section{Assessing the potential impact of spacers/VHCs on drug delivery}

The use of a spacer/VHC is one link in the chain of processes necessary to establish an optimal outcome when pMDIs are used for therapy, namely that the maximal quantity of the respirable aerosol fraction (particles with an aerodynamic diameter $\leqslant 5 \mu \mathrm{m}$ ) is delivered regularly to the airways rather than elsewhere. Assessing the contribution of this particular link to the overall management and clinical outcomes of patients with obstructive airway disease in the "real world" is a considerable challenge.

With regard to studies addressing the intrinsic efficacy of spacers/VHCs, most are in vitro studies using filters and/or cascade impactors to estimate how the spacer/VHC affects the respirable or fine-particle fraction of the dose emitted from the pMDI. Some studies are refined by "models" of the human oropharynx and airways. Using such approaches, available evidence would suggest that the use of a spacer/ VHC of any reasonable construction and design (including disposable devices [41] and homemade, ad hoc devices such as bottomless plastic bottles and toilet paper rolls) significantly reduces the large-particle fraction (that likely to impact in the mouth and throat) and maximises the fine-particle fraction delivered to the airways from a pMDI, although the degree of this effect varies with the device $[42,43]$ and the fine-particle fraction may represent a lower fraction of the total dosage than when a spacer/VHC is not used at all $[23,44-54]$. Some studies suggest no more than a marginal effect of specific spacers/VHCs on the fine-particle fraction output $[55,56]$. Reduction of oropharyngeal deposition of particles likely minimises local/topical unwanted effects (hoarseness or oral thrush) but may increase systemic absorption of the drug [57]. There are few substantial studies that estimate the magnitude and clinical impact of these 
effects in real life [58]: most of these address the effects of spacers/VHCs on the bronchodilatation produced by short-acting $\beta$-agonists (and do suggest a measurable effect, even in patients with good pMDI technique) [50, 59], although some address the effects of inhaled corticosteroids. Devices made of antistatic materials further increase the delivery of the respirable particle fraction $[46,51,52,60]$, although again the effects are sometimes marginal $[55,56,61]$, and the clinical consequences of this for real-life disease control are unclear.

Finally, when considering real-life outcomes of using spacers/VHCs, it is clear that many other influences may potentially affect these, including the precise pMDI-spacer/VHC combination being used, spacer/ VHC priming and maintenance, aspects of inhaler technique uninfluenced by spacers/VHCs, and the compliance of the patient with spacer/VHC usage and prescribed therapy in general $[26,62-66]$.

The hitherto discussed potential advantages and disadvantages of using a spacer/VHC are summarised in table 2 .

\section{Recommendations on how to use a spacer/VHC properly}

While the fine details of the usage of individual devices may vary, a number of universal and important principles emerging from the literature form the basis of the following recommendations.

\section{Recommendations}

1) Sit or stand up straight with the chin up and the neck slightly extended.

2) Shake the pMDI five times and remove its cap.

3) If using a valved spacer, shake it to check that the valve(s) is not stuck.

4) Hold the pMDI upright (with the canister up) and fit it into the spacer/VHC. Hold the pMDI-spacer/VHC assembly horizontal, with one hand holding the pMDI between the index finger and thumb, and the other hand supporting the mouthpiece end of the spacer/VHC.

5) Breathe out as far as is comfortable.

6) Place the spacer/VHC mouthpiece between the teeth and seal the lips around it (or place the mask gently but tightly over the nose and lips).

7) Breathe in slowly, immediately press the inhaler once and continue to breathe in slowly (over $4-5 \mathrm{~s}$ ) until the lungs are full.

8) Hold the breath for $10 \mathrm{~s}$ or for as long as is comfortable. While breath holding, take the spacer/VHC out of the mouth (or lower the mask) and relax.

9) When further doses are required, the entire sequence must be repeated for each additional dose, including shaking the pMDI if necessary. Multiple doses should never be fired together into the spacer/VHC and be inhaled with a single breath.

10) When the session is ended, take the pMDI out of the spacer/VHC port, place the cap back on the pMDI, and rinse the mouth and gargle after inhalation of a corticosteroid.

\section{TABLE 2 Advantages and disadvantages of a spacer/valved holding chamber (VHC)}

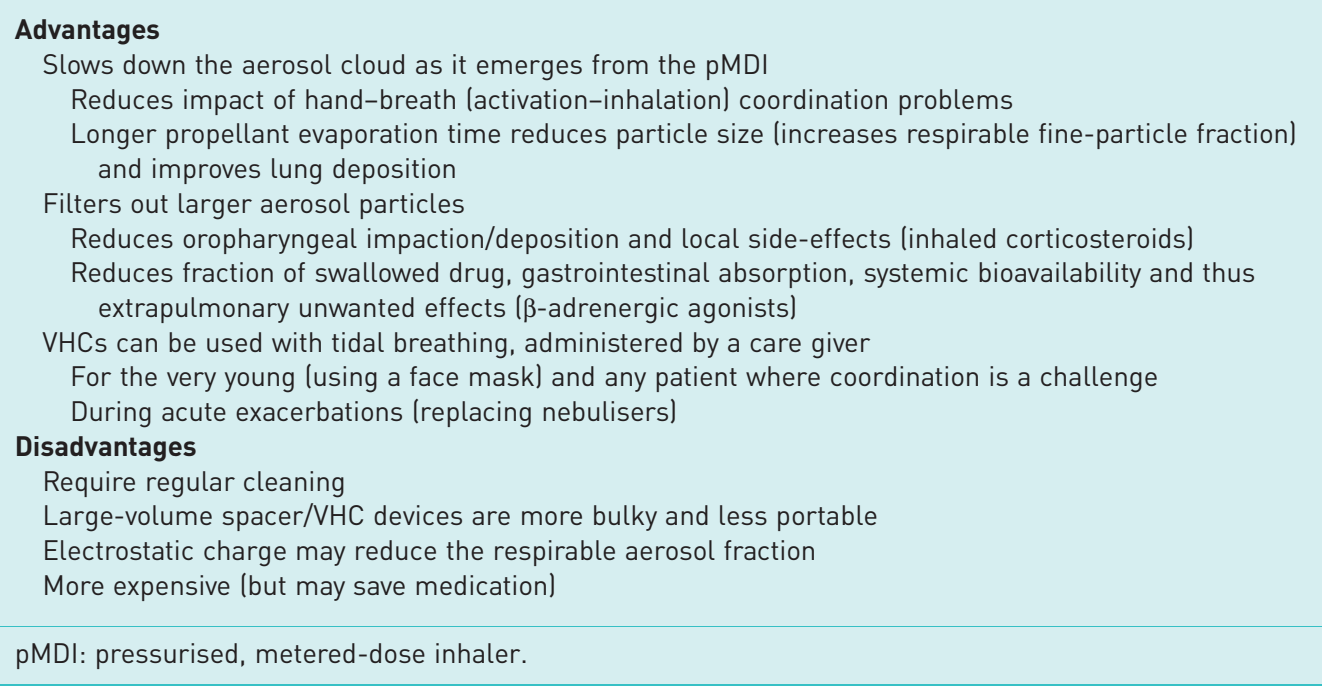


Notes on the recommendations

- It is important that there is little or no delay between activating the pMDI and breathing in through the spacer/VHC. While slowing of the aerosol allows evaporation of the particles and increases the respirable particle fraction, too long a delay in breathing in $(\geqslant 10 \mathrm{~s})$ significantly reduces it [46, 66-69]. Activating the pMDI before inhaling or during expiration may further reduce drug delivery [45]. Thus, some coordination between activation of the pMDI and inhalation is still desirable, even with a spacer/ VHC.

- When breathing in from a spacer/VHC, a single slow and deep inhalation followed by a breath hold is optimal [2, 70]. A minimum flow rate of $15 \mathrm{~L} \cdot \mathrm{min}^{-1}$ is acceptable while $30 \mathrm{~L} \cdot \mathrm{min}^{-1}$ is optimal $[17,25,71]$.

- If the patient is not able to inhale with a slow and deep breath, tidal breathing appears to be the alternative manoeuvre of choice; some studies in children have suggested that this technique is of equivalent efficacy [72], while others suggest it is inferior [73].

- If tidal breathing is employed, the pMDI should be activated at the beginning of a tidal inhalation [74]. Studies in children suggest that two tidal breaths are sufficient to empty a small-volume spacer/VHC, while three are needed for a larger volume spacer/VHC [74-76]. Note that the inspiratory flow generated by very young children during tidal breathing may be insufficient to open the valves of some VHCs [71].

- Multiple activations of the pMDI into the spacer/VHC before inhalation create turbulence and significantly reduce the respirable fraction of the aerosol [66-68, 77].

- Although spacers/VHCs significantly remove larger, nonrespirable particles and thus reduce their oropharyngeal deposition, they do not obviate the need to rinse the mouth and gargle after inhalation of a corticosteroid, especially for those patients for whom a spacer/VHC was prescribed to overcome hoarseness or thrush.

\section{Recommendations on spacer/VHC maintenance}

There are no universal recommendations for spacer/VHC maintenance; leaflets are often provided by manufacturers but advice varies. Some of the advice hereunder is therefore empirical and not based on clinical trial evidence, although there is evidence that poor maintenance and understanding of spacer/ VHC etiquette impacts unfavourably on efficient delivery of inhaled medication [18]

Spacers/VHCs are potentially subject to microbial contamination and, since they come into contact with mucous membranes, it has been argued that they should be cleaned, disinfected, rinsed and air-dried after each use [78]. Bacterial contamination of spacers/VHCs appears to be common; for example, in one study, contamination with Pseudomonas aeruginosa, Staphylococcus aureus and Klebsiella pneumoniae was detected in $35 \%$ of spacers/VHCs used by asthmatic children [79]. The clinical sequelae, if any, are not clear, and the principle of thoroughly cleaning the spacer/VHC after each and every use is neither practised nor recommended in manufacturers' instructions. Nevertheless, it would at least seem prudent not to share devices between individuals.

Spacers/VHCs fabricated with nonconducting plastic materials accumulate internal electrostatic charge, which may significantly reduce the drug aerosol available for inhalation [80]. This electrostatic charge can be reduced with antistatic agents $[67,68,81]$ or, more simply, by washing the inner surface with ordinary household ionic detergent [82]. This also keeps the device clean and presumably minimises contamination with microorganisms. Spacers/VHCs made of conducting (metal) materials are not susceptible to static charge $[67,68]$, but still need cleaning. New nonconducting spacers/VHCs should therefore be washed before their first use. All spacers/VHCs should subsequently be washed at least monthly and preferably weekly.

Table 3 lists the different steps in the washing and cleaning procedure. The spacer/VHC should be disassembled and washed by hand (never in the dishwasher), by immersion and vigorous shaking in cold

\section{TABLE 3 Washing and cleaning a spacer/valved holding chamber (VHC)}

1) Disassemble the spacer/VHC after the last dose of the day

2) Immerse the parts in lukewarm tap water containing a few drops of household detergent

3) Shake the parts in the water and rub them with a soft cloth

4) Leave the parts soaking for $15 \mathrm{~min}$, then take them out of the water

5) Do not rinse or dry rub the inside of the parts

6) Rinse soapy water off the mouthpiece

7) Place the parts on a clean towel to air-dry overnight

8) Reassemble the parts the next morning and check that the valve is not stuck

9) Wash your spacer/VHC every week 
or lukewarm tap water containing a small amount of simple, household ionic detergent [83]. While still underwater, the spacer/VHC parts may be wiped with a soft cloth but not scrubbed. Once cleaned, they should be left to soak for $15 \mathrm{~min}$, then be taken out of the water, placed on a clean towel without rinsing and left to air-dry (washing the device last thing at night is therefore a good time). This allows the detergent to form a thin, antistatic layer on the inner surface of the spacer/VHC. In contrast to the spacer/ VHC, it may be advisable to rinse the soapy water off the mouthpiece to get rid of the taste and because of the potential for developing contact dermatitis from the detergent [78]. Spacers/VHCs made of conducting, antistatic material may be rinsed both on the outside and inside before air drying overnight. After drying overnight, the spacer/VHC should be reassembled with a check to see that the valves, if any, are not stuck. The outside surface of the spacer/VHC may be cleaned more regularly when necessary.

"Priming" of the spacer/VHC by repeatedly firing aerosol from the pMDI into it without inhaling also reduces the electrostatic charge on the inner wall of nonconducting (plastic) spacers/VHCs. With each puff, lubricants in the aerosol coat the inner surface of the spacer/VHC with an antistatic lining, which significantly reduces subsequent adherence of the aerosol during routine use [31]. This practice is often recommended before first using a new nonconducting spacer/VHC and after each cleaning session. Despite the theoretical advantages of this procedure, its real-life clinical implications are again unclear and it is wasteful of expensive medication [84]. Some manufacturers' leaflets recommend priming with 15-20 puffs of medication, which is certainly excessive. It appears reasonable to assume that no more than one or two puffs after each cleaning session is sufficient. Regular (twice daily) use of the pMDI for maintenance therapy will prime it in any case day by day. Conducting (metal) spacers do not need priming at all $[30,82,84]$.

According to manufacturers' leaflets, the lifetime of a spacer/VHC varies between 6 and 12 months. Spacers/VHCs should, therefore, be replaced at least annually.

\section{Conclusions}

An editorial written 25 years ago advocated more widespread use of spacers/VHCs [85] and today, the message remains unchanged. In view of the many advantages and few disadvantages of spacers/VHCs, every patient treated with a pMDI should own and regularly use a spacer/VHC, and know how to use it properly, both for routine preventer therapy and in an emergency, and how to keep it clean and keep an eye out for faults.

This implies that healthcare professionals should be empowered and motivated to impart this knowledge in a uniform, systematic way as part of the routine management of obstructive airway diseases. Since apparently only a small minority $(\sim 10 \%)$ of healthcare professionals appears to be capable of teaching patients how to use inhaler devices, including spacers, properly [86], the need for recommendations for use and maintenance, as well as training and teaching, would appear as pressing as ever.

Further research is necessary to define more precisely the clinical benefits of the use of spacers/VHCs in the real world, which will in turn allow estimation of their cost effectiveness. Finally, notwithstanding the best intentions of healthcare professionals, there must be continued awareness of the question of whether or not patients really use them and their possible impact, positive or negative, on compliance with inhaled medication in general.

Author contributions: All of the authors contributed to researching, collating and writing this paper. W. Vincken led the literature search and collated the findings. M.L. Levy also checked and formatted the references appropriately. J. Scullion, O.S. Usmani and P.N.R. Dekhuijzen also paid particular attention to the clinical protocols. C.J. Corrigan was also responsible for the final layout and wording of the manuscript.

Conflict of interest: M.L. Levy reports receiving consultancy fees from Clement Clarke International, and personal fees for lectures and conference accommodation from Teva and AstraZeneca, is a board member of the Global Initiative for Asthma (GINA), and has received reimbursement for travel and accommodation expenses from GINA, has received funding from Chiesi for the DSMB, Triple, Forward, Trigger and Trimeran studies, and accommodation support from Chiesis to attend the ERS International Congress in 2017, has received an education grant from Consorzio Futuro in Ricerca for the ADMIT group, attended advisory board meetings with AstraZeneca in January 2018 and with Boehringer Ingelheim in November 2017, and has received lecture fees from Soar Beyond outside the submitted work. J. Scullion reports receiving honoraria for attending meetings from AstraZeneca, Chiesi, Teva, Boehringher Ingelheim, Pfizer, Mylan, Trudell, Nutricia and Sandoz, and support for a meeting from Roche, outside the submitted work. C.J. Corrigan reports attending an open day at GlaxoSmithKline headquarters, outside the submitted work.

Support statement: The Aerosol Drug Management Improvement Team (ADMIT) is a group of European respiratory physicians with a common interest in promoting excellence in the delivery of inhaled drugs for asthma and COPD. It is supported by an unrestricted educational grant from the Consorzio Futuro In Ricerca. Members of ADMIT receive compensation for attending meetings. 


\section{References}

1 Crompton GK. Problems patients have using pressurized aerosol inhalers. Eur J Respir Dis 1982; 63: Suppl. 119, 101-104.

2 Newman SP, Pavia D, Garland N, et al. Effects of various inhalation modes on the deposition of radioactive pressurized aerosols. Eur J Respir Dis 1982; 63: Suppl. 119, 57-65.

3 Franklin W, Lowell FC, Michelson AL, et al. Aerosolized steroids in bronchial asthma. J Allergy 1958; 29: 214-221.

4 Stein SW, Thiel CG. The history of therapeutic aerosols: a chronological review. J Aerosol Med Pulm Drug Deliv 2016; 30: 20-41.

5 Newman SP, Woodman G, Clarke SW, et al. Effect of InspirEase on the deposition of metered-dose aerosols in the human respiratory tract. Chest 1986; 89: 551-556.

6 Pool JB, Greenough A, Gleeson JG, et al. Inhaled bronchodilator treatment via the nebuhaler in young asthmatic patients. Arch Dis Child 1988; 63: 288-291.

$7 \quad$ Rau JL. Practical problems with aerosol therapy in COPD. Respir Care 2006; 51: 158-172.

8 Cates CJ, Welsh EJ, Rowe BH. Holding chambers (spacers) versus nebulisers for beta-agonist treatment of acute asthma. Cochrane Database Syst Rev 2013; 9: CD000052.

9 Cates CJ, Crilly JA, Rowe BH. Holding chambers (spacers) versus nebulisers for beta-agonist treatment of acute asthma. Cochrane Database Syst Rev 2006; 2: CD000052.

10 Salyer JW, DiBlasi RM, Crotwell DN, et al. The conversion to metered-dose inhaler with valved holding chamber to administer inhaled albuterol: a pediatric hospital experience. Respir Care 2008; 53: 338-345.

11 van Geffen WH, Douma WR, Slebos DJ, et al. Bronchodilators delivered by nebuliser versus pMDI with spacer or DPI for exacerbations of COPD. Cochrane Database Syst Rev 2016; 8: CD011826.

12 Hendeles L, Hatton RC, Coons TJ, et al. Automatic replacement of albuterol nebulizer therapy by metered-dose inhaler and valved holding chamber. Am J Health Syst Pharm 2005; 62: 1053-1061.

13 Dekhuijzen PN, Bjermer L, Lavorini F, et al. Guidance on handheld inhalers in asthma and COPD guidelines. Respir Med 2014; 108: 694-700.

14 Roche N, Dekhuiizen PN. The evolution of pressurized metered-dose inhalers from early to modern devices. J Aerosol Med Pulm Drug Deliv 2016; 29: 311-327.

15 Guss D, Barash IA, Castillo EM. Characteristics of spacer device use by patients with asthma and COPD. J Emerg Med 2008; 35: 357-361.

16 Bryant L, Bang C, Chew C, et al. Adequacy of inhaler technique used by people with asthma or chronic obstructive pulmonary disease. J Prim Health Care 2013; 5: 191-198.

17 Newman SP. Spacer devices for metered dose inhalers. Clin Pharmacokinet 2004; 43: 349-360.

18 Mitchell JP, Nagel MW. Valved holding chambers (VHCs) for use with pressurised metered-dose inhalers (pMDIs): a review of causes of inconsistent medication delivery. Prim Care Respir J 2007; 16: 207-214.

19 Lavorini F, Fontana GA. Targeting drugs to the airways: the role of spacer devices. Expert Opin Drug Deliv 2009; 6: 91-102.

20 Laube BL, Janssens HM, De Jongh FHC, et al. What the pulmonary specialist should know about the new inhalation therapies. Eur Respir J 2011; 37: 1308-1331.

21 Amirav I. Focus on pMDI and VHC; past, present, future. J Aerosol Med Pulm Drug Deliv 2014; 27: Suppl. 1, S1-S3.

22 Fink JB. Aerosol device selection: evidence to practice. Respir Care 2000; 45: 874-875.

23 Nagel MW, Wiersema KJ, Bates SL, et al. Performance of large- and small-volume valved holding chambers with a new combination long-term bronchodilator/anti-inflammatory formulation delivered by pressurized metered dose inhaler. J Aerosol Med 2002; 15: 427-433.

24 Verbanck S, Vervaet C, Schuermans D, et al. Aerosol profile extracted from spacers as a determinant of actual dose. Pharm Res 2004; 21: 2213-2218.

25 Ogrodnik N, Azzi V, Sprigge E, et al. Nonuniform deposition of pressurized metered-dose aerosol in spacer devices. J Aerosol Med Pulm Drug Deliv 2016; 29: 490-500.

26 Dubus JC, Dolovich M. Emitted doses of salbutamol pressurized metered-dose inhaler from five different plastic spacer devices. Fundam Clin Pharmacol 2000; 14: 219-224.

27 Reginato R, Amantea SL, Krumenauer R. Pressure gradient and inspiratory times required for valve opening of various holding chambers. Allergy Asthma Proc 2011; 32: 137-141.

28 Dewsbury NJ, Kenyon CJ, Newman SP. The effect of handling techniques on electrostatic charge on spacer devices: A correlation with in vitro particle size analysis. Int J Pharm 1996; 137: 261-264.

29 Kenyon CJ, Thorsson L, Borgstrom L, et al. The effects of static charge in spacer devices on glucocorticosteroid aerosol deposition in asthmatic patients. Eur Respir J 1998; 11: 606-610.

30 Janssens HM, Devadason SG, Hop WCJ, et al. Variability of aerosol delivery via spacer devices in young asthmatic children in daily life. Eur Respir J 1999; 13: 787-791.

31 Bisgaard H, Anhoj J, Klug B, et al. A non-electrostatic spacer for aerosol delivery. Arch Dis Child 1995; 73: 226-230.

32 Williams RO, Patel AM, Barron MK, et al. Investigation of some commercially available spacer devices for the delivery of glucocorticoid steroids from a pMDI. Drug Develop Ind Pharm 2001; 27: 401-412.

33 Dubus JC, Guillot C, Badier M. Electrostatic charge on spacer devices and salbutamol response in young children. Int J Pharm 2003; 261: 159-164.

34 Khan Y, Tang Y, Hochhaus G, et al. Lung bioavailability of hydrofluoroalkane fluticasone in young children when delivered by an antistatic chamber/mask. J Pediatr 2006; 149: 793-797.

35 Ditcham W, Murdzoska J, Zhang G, et al. Lung deposition of ${ }^{99 \mathrm{~m}} \mathrm{Tc}$-radiolabeled albuterol delivered through a pressurized metered dose inhaler and spacer with facemask or mouthpiece in children with asthma. J Aerosol Med Pulm Drug Deliv 2014; 27: Suppl. 1, S63-S75.

36 Amirav I, Newhouse MT. Aerosol therapy with valved holding chambers in young children: importance of the facemask seal. Pediatrics 2001; 108: 389-394.

37 Janssens HM, Tiddens HA. Facemasks and aerosol delivery by metered dose inhaler-valved holding chamber in young children: a tight seal makes the difference. J Aerosol Med 2007; 20: Suppl. 1, S59-S63.

38 Morton RW, Mitchell JP. Design of facemasks for delivery of aerosol-based medication via pressurized metered dose inhaler with valved holding chamber: key issues that affect performance. J Aerosol Med 2007; 20: Suppl. 1 , S29-S42. 
39 Nikander K, Berg E, Smaldone GC. Jet nebulizers versus pressurized metered dose inhalers with valved holding chambers: effects of the facemask on aerosol delivery. J Aerosol Med 2007; 20: Suppl. 1, S46-S55.

40 Amirav I, Newhouse MT. Review of optimal characteristics of face-masks for valved-holding chambers (VHCs). Pediatr Pulmonol 2008; 43: 268-274.

41 Sanders M, Bruin R. A rationale for going back to the future: use of disposable spacers for pressurised metered dose inhalers. Pulm Med 2015; 2015: 176194.

42 Finlay WH, Zuberbuhler P. In vitro comparison of beclomethasone and salbutamol metered-dose inhaler aerosols inhaled during pediatric tidal breathing from four valved holding chambers. Chest 1998; 114: 1676-1680.

43 Finlay WH, Zuberbuhler P. In vitro comparison of salbutamol hydrofluoroalkane (Airomir) metered dose inhaler aerosols inhaled during pediatric tidal breathing from five valved holding chambers. J Aerosol Med 1999; 12 285-291.

44 Dalby RN, Somaraju S, Chavan VS, et al. Evaluation of aerosol drug output from the OptiChamber and AeroChamber spacers in a model system. J Asthma 1998; 35: 173-177.

45 Wilkes W, Fink J, Dhand R. Selecting an accessory device with a metered-dose inhaler: variable influence of accessory devices on fine particle dose, throat deposition, and drug delivery with asynchronous actuation from a metered-dose inhaler. J Aerosol Med 2001; 14: 351-360.

46 Chambers FE, Brown S, Ludzik AJ. Comparative in vitro performance of valved holding chambers with a budesonide/formoterol pressurized metered-dose inhaler. Allergy Asthma Proc 2009; 30: 424-432.

47 Leach CL, Colice GL. A pilot study to assess lung deposition of HFA-beclomethasone and CFC-beclomethasone from a pressurized metered dose inhaler with and without add-on spacers and using varying breathhold times. J Aerosol Med Pulm Drug Deliv 2010; 23: 355-361.

48 Lavorini F, Mannini C, Chellini E, et al. Optimising inhaled pharmacotherapy for elderly patients with chronic obstructive pulmonary disease: the importance of delivery devices. Drugs Aging 2016; 33: 461-473.

49 Kissoon N, Teelucksingh S, Blake KV, et al. Plastic bottles as spacers for a pressurized metered-dose inhaler: in vitro characteristics. West Indian Med J 2001; 50: 189-193.

50 Rodriguez-Martinez CE, Sossa-Briceno MP, Castro-Rodriguez JA. Comparison of the bronchodilating effects of albuterol delivered by valved vs. non-valved spacers in pediatric asthma. Pediatr Allergy Immunol 2012; 23: $629-635$.

51 Goncalves TM, Alhanout K, Nicolay A, et al. Comparative in vitro performance of three small-volume valved holding chambers with beclomethasone/formoterol pressurized metered dose inhaler. J Aerosol Med Pulm Drug Deliv 2013; 26: 223-227.

52 Hatley RH, von Hollen D, Sandell D, et al. In vitro characterization of the OptiChamber Diamond valved holding chamber. J Aerosol Med Pulm Drug Deliv 2014; 27: Suppl. 1, S24-S36.

53 Sheth $\mathrm{P}$, Bertsch MD, Knapp CL, et al. In vitro evaluation of nonconventional accessory devices for pressurized metered-dose inhalers. Ann Allergy Asthma Immunol 2014; 113: 55-62.

54 Johnson JL, Guthrie D, Hyde J, et al. The effect of a holding chamber on albuterol metered-dose inhaler product differences. Ann Allergy Asthma Immunol 2016; 117: 246-250.

55 Kelly HW, Ahrens RC, Holmes M, et al. Evaluation of particle size distribution of salmeterol administered via metered-dose inhaler with and without valved holding chambers. Ann Allergy Asthma Immunol 2001; 87: 482-487.

56 Crim C, Holmes M, Lee B, et al. Evaluation of particle size distribution of albuterol sulfate hydrofluoroalkane administered via metered-dose inhaler with and without valved holding chambers. Ann Allergy Asthma Immunol 2005; 94: 80-85.

57 Dempsey OJ, Wilson AM, Coutie WJ, et al. Evaluation of the effect of a large volume spacer on the systemic bioactivity of fluticasone propionate metered-dose inhaler. Chest 1999; 116: 935-940.

58 Gachelin E, Vecellio L, Dubus JC. Evaluation critique des chambres d'inhalation commercialisées en France [Critical evaluation of inhalation spacer devices available in France]. Rev Mal Respir 2015; 32: 672-681.

59 Fontana GA, Lavorini F, Chiostri M, et al. Large and small airway responses to procaterol hydrochloride administered through different extension devices in asthmatic patients. J Aerosol Med 1999; 12: 177-185.

60 Louca E, Leung K, Coates AL, et al. Comparison of three valved holding chambers for the delivery of fluticasone propionate-HFA to an infant face model. J Aerosol Med 2006; 19: 160-167.

61 Coppolo DP, Mitchell JP, Nagel MW. Levalbuterol aerosol delivery with a nonelectrostatic versus a nonconducting valved holding chamber. Respir Care 2006; 51: 511-514.

62 Barry PW, O'Callaghan C. Inhalational drug delivery from seven different spacer devices. Thorax 1996; 51: 835-840.

63 Asmus MJ, Liang J, Coowanitwong I, et al. In vitro deposition of fluticasone aerosol from a metered-dose inhaler with and without two common valved holding chambers. Ann Allergy Asthma Immunol 2002; 88: 204-208.

64 Asmus MJ, Coowanitwong I, Kwon SH, et al. In vitro performance of two common valved holding chambers with a chlorofluorocarbon-free beclomethasone metered-dose inhaler. Pharmacotherapy 2003; 23: 1538-1544.

65 Asmus MJ, Liang J, Coowanitwong I, et al. In vitro performance characteristics of valved holding chamber and spacer devices with a fluticasone metered-dose inhaler. Pharmacotherapy 2004; 24: 159-166.

66 O'Callaghan C, Barry P. Spacer devices in the treatment of asthma. BMJ 1997; 314: 1061-1062.

67 O'Callaghan C, Lynch J, Cant M, et al. Improvement in sodium cromoglycate delivery from a spacer by use of an antistatic lining, immediate inhallation and avoiding multiple actuations of drug. Thorax 1993; 48: 603-606.

68 Barry PW, O'Callaghan C. The effect of delay, multiple actuations and spacer static charge on the in vitro delivery of budesonide from the Nebuhaler. Br J Clin Pharmacol 1995; 40: 76-78.

69 Slator L, von Hollen D, Sandell D, et al. In vitro comparison of the effect of inhalation delay and flow rate on the emitted dose from three valved holding chambers. J Aerosol Med Pulm Drug Deliv. 2014; 27: Suppl. 1, S37-S43.

70 Nikander K, Nicholls C, Denyer J, et al. The evolution of spacers and valved holding chambers. J Aerosol Med Pulm Drug Deliv 2014; 27: Suppl. 1, S4-S23.

71 Haidl P, Heindl S, Siemon K, et al. Inhalation device requirements for patients' inhalation maneuvers. Respir Med 2016; 118: 65-75.

72 Stephen D, Vatsa M, Lodha R, et al. A randomized controlled trial of 2 inhalation methods when using a pressurized metered dose inhaler with valved holding chamber. Respir Care 2015; 60: 1743-1748. 

asthmatic children. Eur Respir J 2007; 29: 299-306.

74 Berlinski A, von Hollen D, Hatley RHM, et al. Drug delivery in asthmatic children following coordinated and uncoordinated inhalation maneuvers: a randomized crossover trial. J Aerosol Med Pulm Drug Deliv 2017; 30: $182-189$.

75 Schultz A, Le Souef TJ, Venter A, et al. Aerosol inhalation from spacers and valved holding chambers requires few tidal breaths for children. Pediatrics 2010; 126: e1493-e1498.

76 Minh KT, von Hollen D, von Konigslow AJ, et al. An instrumented valved holding chamber with facemask to measure application forces and flow in young asthmatic children. J Aerosol Med Pulm Drug Deliv. 2014; 27: Suppl. 1, S55-S62.

77 Rau JL, Restrepo RD, Deshpande V. Inhalation of single $v s$ multiple metered-dose bronchodilator actuations from reservoir devices. An in vitro study. Chest 1996; 109: 969-974.

78 O'Malley CA. Device cleaning and infection control in aerosol therapy. Respir Care 2015; 60: $917-927$.

79 Cohen HA, Cohen Z, Pomeranz AS, et al. Bacterial contamination of spacer devices used by asthmatic children. J Asthma 2005; 42: 169-172.

80 Wildhaber JH, Devadason SG, Eber E, et al. Effect of electrostatic charge, flow, delay and multiple actuations on the in vitro delivery of salbutamol from different small volume spacers for infants. Thorax 1996; 51: 985-988.

81 Gogtay JA. Inhaler device options in a rapidly changing world: addressing physician and patient needs. Respir Drug Deliv 2014; 1: 119-130.

82 Wildhaber JH, Waterer GW, Hall GL, et al. Reducing electrostatic charge on spacer devices and bronchodilator response. Br J Clin Pharm 2000; 50: 277-280.

83 Piérart F, Wildhaber JH, Vrancken I, et al. Washing plastic spacers in household detergent reduces electrostatic charge and greatly improves delivery. Eur Respir J 1999; 13: 673-678.

84 Levy ML, Dekhuijzen PNR, Barnes PJ, et al. Inhaler technique: facts and fantasies. A view from the Aerosol Drug Management Improvement Team (ADMIT). NPJ Prim Care Respir Med 2016; 26: 16017.

85 Keeley D. Large volume plastic spacers in asthma. BMJ 1992; 305: 598-599.

86 Goodwin R, Chander T, Shah N, et al. Inhaler counseling, the real deal or just fresh air? Arch Dis Child 2016 ; 101 : e2. 